\title{
Porta-enxertos para tangerineiras em Santa Catarina
}

\author{
Eduardo Cesar Brugnara', Rafael Roveri Sabião² e Luana Aparecida Castilho Maro³
}

Resumo - Este informativo aborda os cultivares de citros indicados para uso como porta-enxertos de tangerineiras no estado de Santa Catarina, considerando fundamentais algumas características como a tolerância a fatores bióticos e abióticos negativos, a compatibilidade com as copas, e a quantidade e qualidade das tangerinas produzidas. Como as tangerinas são majoritariamente consumidas como fruta fresca e muitos solos catarinenses são argilosos, a qualidade dos frutos induzida pelo porta-enxerto e a sua tolerância à gomose devem ser sempre observadas. Portanto, 'Cleópatra', 'Sunki', P. trifoliata, 'Flying Dragon' e 'Carrizo' são os indicados para a maior parte das tangerineiras.

Termos para indexação: Citrus; Poncirus; Gomose; Bergamota.

\section{Rootstocks for mandarins in Santa Catarina}

Abstract - This article describes citrus cultivars indicated for use as mandarin rootstocks in the state of Santa Catarina, considering fundamental some characteristics like tolerance to negative biotic and abiotic factors, compatibility with scions, and the quantity and quality of fruit. As mandarins are mostly consumed as fresh fruit and many Santa Catarina soils are clayey, the quality induced to the fruits by the rootstock and the tolerance to gummosis must always be observed. Therefore, 'Cleópatra', 'Sunki', P. trifoliata, 'Flying Dragon' and 'Carrizo' are recommended for most mandarins scions.

Index-terms: Citrus; Poncirus; Gummosis; Tangerine.

\section{Introdução}

As tangerineiras são um grupo de variedades de citros caracterizadas pela baixa aderência entre gomos e entre gomos e casca, que facilita seu consumo. O termo "tangerinas" se refere a diferentes espécies. As mais importantes em termos econômicos são Citrus reticulata Blanco ('Ponkan', 'Cravo'), Citrus deliciosa Ten. ('Montenegrina', 'Mexerica do Rio'), Citrus unshiu Marc ('Satsuma Okitsu') e Citrus clementina Hort ex. Tan ('Clemenules'), e alguns híbridos como o 'Murcott'.

As tangerinas e os citros em geral são propagados vegetativamente através da enxertia, técnica largamente utilizada na produção de mudas. $O$ uso desse tipo de propagação permite a formação de um clone, grupo de plantas provenientes de uma matriz em comum, ou seja, com constituição genética uniforme. As plantas originadas de sementes, também conhecidas como pé-francos, possuem inúmeras desvantagens, tais como: heterogeneidade entre plantas devido à segregação genética; frutificação mais tardia e porte elevado que dificulta a realização dos tratos culturais; irregularidade de produção, cor, características organolépticas e tamanho entre plantas (FACHINELLO, 1995).

A produção de mudas enxertadas possibilitou a obtenção de plantas de menor porte, com espinhos menores, início de produção precoce, e, com a formação de clones, uma maior adaptação aos diferentes ambientes e sistemas de produção, além de tolerância a doenças, proporcionada por meio da seleção adequada do porta-enxerto de acordo com sua tolerância a fatores bióticos e abióticos.

A enxertia consiste em colocar em contato duas porções de tecido vegetal de tal forma que se unam e, posteriormente, se desenvolvam, originando uma nova planta. A planta cítrica propagada por enxertia é composta, basicamente, de duas partes: o enxerto ou o garfo e o porta-enxerto ou o cavalo, ainda que eventualmente possa ser utilizada uma porção intermediária ao enxerto e porta-enxerto, chamada de interenxerto, enxerto intermediário ou filtro. O enxerto é a parte representada por um fragmento da planta, contendo uma gema, responsável pela formação da parte aérea da nova planta (copa). Já o porta-enxerto é a parte responsável pela formação do sistema radicular e que, pelas razões acima citadas, no caso dos citros, pode ser advindo de semente.

Mesmo com as desvantagens da propagação por sementes, elas são utilizadas na formação de porta-enxertos de citros graças à ocorrência da poliembrionia nucelar e também da apomixia em alta freqüência nas sementes de porta-enxertos selecionados. Conforme descrito por Carvalho et al. (2005), além do embrião sexual, originado da fusão dos gametas masculino e feminino, as sementes de citros podem apresentar embriões apomíticos, formados a partir do tecido da nucela. Por ser a nucela parte exclusivamente materna da semente, os embriões nucelares pos-

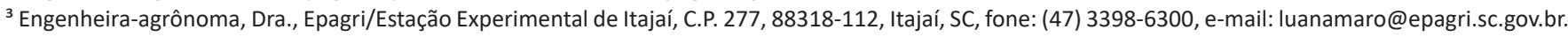


suem a mesma constituição genética da planta que a origina, possibilitando, assim, a produção de plantas idênticas (clones). Além disso, como não há formação de vasos condutores suficientes para a translocação dos patógenos para os embriões, é possível obter plantas livres de vírus. As outras desvantagens da utilização de sementes são contornadas pela enxertia.

Como é possível escolher o portaenxerto dentre uma série de espécies e cultivares, dá-se preferência àqueles que tragam alguma vantagem na fase de viveiro e pomar. Na copa, o portaenxerto influencia o vigor, o tamanho da planta, a precocidade de entrada em produção, a produtividade, a qualidade dos frutos, a época de maturação, a resistência ao frio, entre outros. Além disso, o porta-enxerto pode variar em tolerância a fatores estressantes do solo como deficiência hídrica e nutricional, alagamento, salinidade, pragas e doenças (POMPEU JUNIOR, 2005).

\section{História do uso de porta-}

\section{enxertos de citros}

A citricultura brasileira até o final do século XIX fundava-se sobre péfrancos. No início do século $X X$, com a alta no consumo e a exportação, houve a expansão do cultivo, principalmente com plantio de mudas enxertadas, de raiz nua, da laranjeira 'Caipira' [C. sinensis (L.) Osb.], que, posteriormente, pela sensibilidade à seca e à gomose causada por Phytophthora sp., foi perdendo espaço para laranjeira-azeda ( $C$. aurantium L.) (DONADIO et al., 2005). A utilização do limoeiro 'Cravo' (C. limonia Osb.) fundamentou-se com aparecimento da "tristeza" no ano de 1937, substituindo a laranjeira-azeda, suscetível àquela doença. O 'Cravo' consolidou-se como principal porta-enxerto, chegando a $99 \%$ dos pomares brasileiros, até o aparecimento da doença declínio dos citros em meados de 1970, que estimulou a diversificação com os porta-enxertos de tangerineira 'Cleópatra' (C. reshni Hort. ex Tan.) e limoeiro 'Volkameriano' (C. volkameriana V. Ten. \& Pasq.). A ocorrência da doença morte súbita dos citros, em 1999, impulsionou ainda mais a diversificação de porta-enxertos, principalmente com 'Cleópatra', citrumeleiro 'Swingle' [C. paradisi Macf. x Poncirus trifoliata (L.) Raf.] e tangerineira 'Sunki' [C. sunki (Hayata) Hort.ex Tan.] (DONADIO et al., 2005; OLIVEIRA et al., 2008). No estado de São Paulo, no ano de 2003 , 40\% dos pomares eram enxertados sobre 'Cravo', 33\% em 'Cleópatra', 14\% em 'Swingle', 7\% em 'Sunki', entre outros (OLIVEIRA et al., 2008). Já em 2018, de acordo com dados não publicados da Coordenadoria de Defesa Agropecuária do Estado de SP, 50\% das mudas dos viveiros estão enxertadas sobre 'Swingle'; 33\% sobre 'Cravo'; 12\% sobre 'Sunki' e 'Cleópatra'; e 4\% sobre trifoliata 'Flying Dragon' (Poncirus trifoliata Raf. var. monstrosa).

Em Santa Catarina, na década de 70 a laranjeira 'Caipira' era o porta-enxerto utilizado para a produção de mudas cítricas. Foi substituída gradativamente pelo 'Cravo' e pelo trifoliata a partir do início dos anos 80, por indicação da pesquisa. Porém, o trifoliata entrou em desuso porque induz crescimento mais lento da planta resultante. Ressalta-se que muitos pomares foram implantados com mudas provenientes do estado de São Paulo. Em 2008, o 'Swingle' já havia assumido o segundo lugar em utilização entre os porta-enxertos, após o limão 'Cravo', este em queda. Os citranges 'C35' e 'Carrizo' (cruzamentos de Citrus sinensis e $P$. trifoliata) e o trifoliata também vem sendo utilizados há pelo menos uma década (KOLLER \& SOPRANO, 2008), porém não se tem informações atualizadas sobre a participação dos porta-enxertos na produção catarinense de mudas.

\section{Porta-enxertos indicados para tangerineiras em}

\section{Santa Catarina}

Como a maior parte da produção de tangerinas visa o mercado de frutas frescas, a influência do porta-enxerto na qualidade, especialmente em tamanho, cor e teor de açúcares, dos frutos produzidos pela copa enxertada nele, é um fator determinante na sua escolha, bem como na sua adaptação ao solo e na resistência a doenças. A resistência à gomose é um fator determinante, pois em Santa Catarina ocorrem solos com médio a alto conteúdo de argila, favoráveis à ocorrência dessa doença.

A seguir são apresentados os portaenxertos indicados para o cultivo de tangerineiras em Santa Catarina (GONZATTO et al., 2018; MARO et al., 2019).

Limoeiro trifoliata - planta de folhas caducas, trifolioladas. Seis cultivares estão registrados no Brasil, incluindo o 'SCS453 Nasato', registrado pela Epagri em 2011 no Sistema Nacional de Cultivares (SNC). Uma variedade botânica da espécie é o Poncirus trifoliata var. monstrosa, de crescimento mais lento. Dentre os quatro cultivares registrados no Brasil, a Epagri detém o denominado 'Flying Dragon'.

Citrangeiro 'Carrizo' - citrangeiros são cruzamentos de laranjeiras-doces com trifoliata. Há onze citrangeiros registrados no Brasil, porém apenas dois levam a denominação Carrizo ('Carrizo', da Epagri, e 'IAC 387 Carrizo', registrado pelo IAC).

Tangerineiras Sunki e Cleópatra - a entrada em produção é mais demorada que nos demais cultivares. São as meIhores opções para enxertar 'Murcott' para cultivo em solos leves. Há doze cultivares registrados no Brasil, entre eles 'Sunki', 'BRS Maravilha' e 'BRS Tropical', sendo o diferencial desses dois últimos materiais o maior número de sementes e maior tolerância à gomose em relação a outras seleções de $C$. sunki.

Citrumeleiro 'Swingle' é um material híbrido entre o pomeleiro 'Duncan' com $P$. trifoliata, com vigor maior que os trifoliatas e citrangeiros, o que pode resultar em frutos de qualidade inferior. Devido à disponibilidade de porta-enxertos indicados no mercado de mudas, o 'Swingle' pode ser uma opção quando a única alternativa disponível for o limoeiro 'Cravo'.

A Figura 1 apresenta fotos de algumas características que auxiliam na identificação a campo e de algumas características importantes para facilmente comparar os porta-enxertos.

\section{Incompatibilidades}

Apesar de a maioria das combinações copa/porta-enxerto ser possível, 


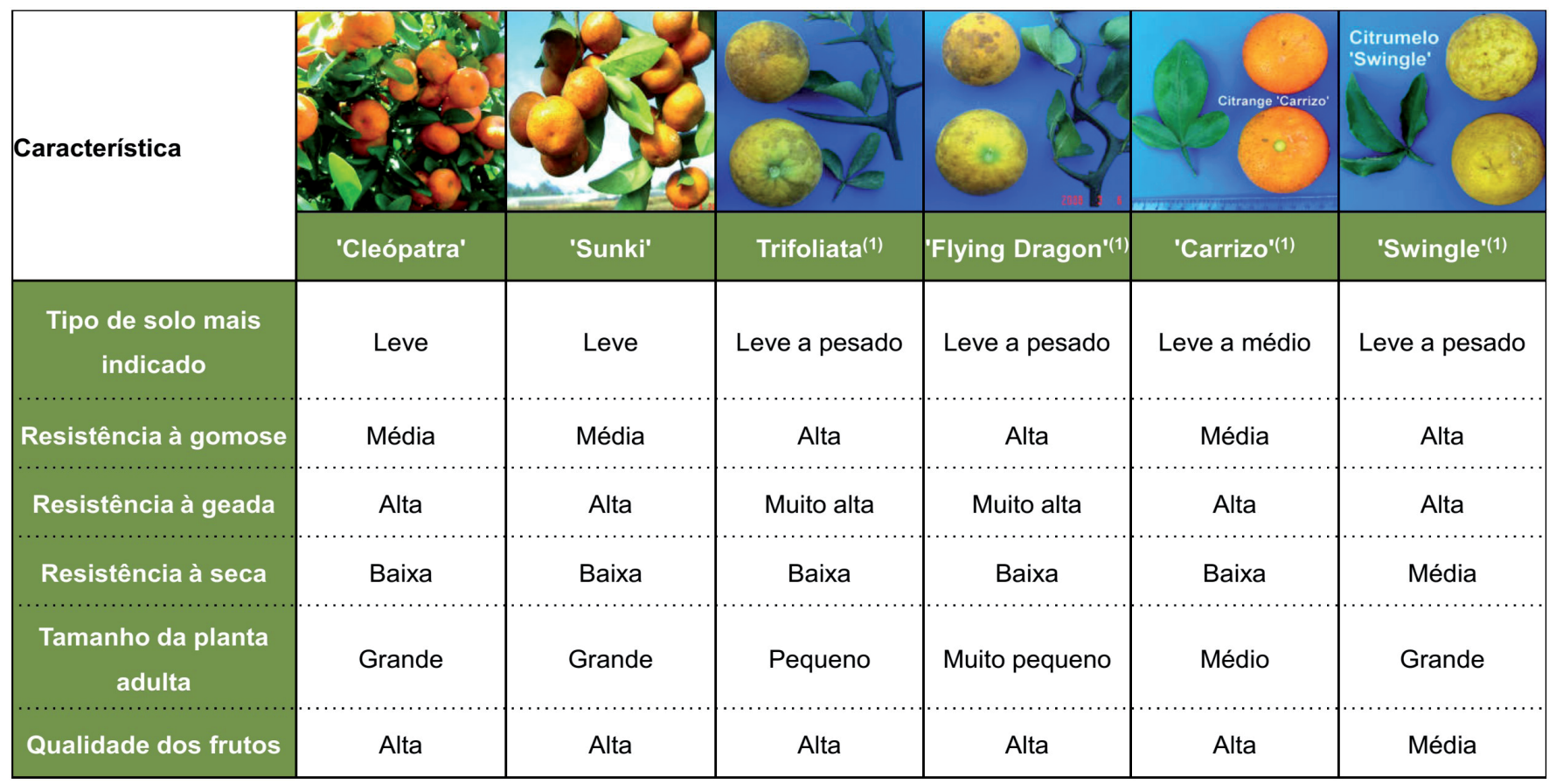

Figura 1. Características dos cultivares de citros que apresentam bom desempenho como porta-enxerto para tangerineiras em Santa Catarina

Figure 1. Characteristics of citrus cultivars with good performance as mandarim rootstocks in Santa Catarina

são reportadas incompatibilidades de satsumas com o citrangeiro 'Troyer' e de tangerineiras híbridas, especialmente o tangoreiro 'Murcott', com porta-enxertos híbridos de trifoliata (CARLOS et al., 1997). As combinações incompatíveis geram plantas que declinam e morrem nos primeiros anos (POMPEU JUNIOR, 2005). No Rio Grande do Sul o 'Murcott' é cultivado e enxertado em trifoliateiro e 'Swingle' sem sintomas evidentes de incompatibilidade, mas com produção de menos frutos por planta (GONZATTO et al., 2018). Em Chapecó - SC, a tangerineira 'SCS458 Osvino' foi cultivada enxertada no 'Troyer' por 15 anos sem evidências de incompatibilidade (BRUGNARA et al., 2012).

\section{Considerações finais}

É importante que as tangerinas apresentem qualidade compatível às exigências do consumidor. Para tanto, devem ser produzidas sobre porta-enxertos compatíveis que confiram aparência e sabor adequados. Os agricultores devem estar atentos ainda às condições de solo, especialmente dos propícios à ocorrência de gomose, buscando sempre porta-enxertos tolerantes. Com base nesses critérios os porta-enxertos
'Cleópatra', 'Sunki', P. trifoliata, 'Flying Dragon' e 'Carrizo' são os mais indicados para a maioria das tangerineiras. Os três últimos devem ser evitados quando a copa for 'Murcott'.

\section{Referências}

BRUGNARA, E. C.; VERONA, L. A. F.; KOLLER, $O$. L. Crescimento de quatro variedades de tangerineiras enxertadas em quatro portaenxertos em Chapecó, SC. In: CONGRESSO BRASILEIRO DE FRUTICULTURA, 22, 2012, Bento Gonçalves, RS. Anais[...]. Bento Gonçalves, RS: Aptor Software, 2012. 1 CD-ROM.

CARLOS, E. F.; STUCHI, E. S.; DONADIO, L. C. Porta-enxertos para a citricultura paulista. Jaboticabal: FUNEP, 1997. 47p.

CARVALHO, S. A.; GRAF, C. C. D.; VIOLANTE, A. R. Produção de material básico e propagação. In: JUNIOR, D. M.; DE NEGRI, J.; PIO, R. M.; POMPEU JUNIOR, J. Citros. Campinas: Instituto Agronômico e Fundag, 2005, p.279316.

DONADIO, L. C., MOURÃO FILHO, F. A. A., MOREIRA, C. S. Centros de origem, distribuição geográfica das plantas cítricas e histórico da citricultura no Brasil. In: MATTOS JÚNIOR, D., DE NEGRI, J. D., PIO, R. M., POMPEU JÚNIOR, J. (Eds). Citros. Campinas: Instituto Agronômico e Fundag, p.1-18, 2005.
FACHINELLO, J. C.; HOFFMANN, A.; NACHTIGAL, J. C.; KERSTEN, E.; FORTES, G. R. L. Propagação de plantas frutíferas de clima temperado. 2. Ed. Pelotas: editora UFPel, 1995. $179 \mathrm{p}$.

GONZATTO, M. P.; OLIVEIRA, R. P.; SOUZA, E. L. S. S; SCHWARZ, S. F.; SOUZA, P. V. D. Portaenxertos. In: EFROM, C. F. S.; SOUZA, P. V. D. (Org.). Citricultura do Rio Grande do Sul: indicações técnicas. 1.ed. Porto Alegre: Secretaria da Agricultura, Pecuária e Irrigação - SEAPI; DDPA, 2018. p.35-60.

KOLLER, O.L.; SOPRANO, E. A Citricultura de Santa Catarina. In: CICLO DE PALESTRAS SOBRE CITRICULTURA DO RS, Alpestre - RS, 15, 2008. Anais..., Porto Alegre: Jade Editora, 2008. 1cd.

MARO, L. A. C.; MARIGUELE, K. H.; BRUGNARA, E. C. Citros. In: EPAGRI. Avaliação de cultivares para o estado de Santa Catarina 2019-2020. Florianópolis: Epagri, 2019. p.31-33 (Epagri. Boletim técnico, 188).

OLIVEIRA, R. P.; FILHO, W. S. S.; PASSOS, O. S.; SCIVITTARO, W. B.; ROCHA, P. S. G. Portaenxertos para citros. Pelotas: Embrapa Clima Temperado, 2008. 45p.

POMPEU JUNIOR, J. Porta-enxertos. In: MATTOS JUNIOR, D.; DE NEGRI, J. G.; PIO, R. M.; POMPEU JUNIOR, J. Citros. Campinas: Instituto Agronômico, 2005. p.63-106. 